SUBJECTIVE WELL-BEING AND ATTITUDE TOWARDS

\title{
EXTERNAL APPEARANCE
}

Popova Larisa, Southern federal university, Rostov-on-Don, Russia.

In recent decades, the problem of subjective well-being has become increasingly relevant in the research of psychologists. This is caused by the acute need for psychological science and practice in determining what serves as the basis for the inner balance of the personality, what it consists of, what emotional-evaluative relationships underlie it, how it participates in the regulation of behavior, how the individual can be helped in solving the problem of well-being. In modern Russian reality in the conditions of the economic crisis, the question of the reaction of citizens to instability, constantly changing and unpredictable living conditions is relevant. The problems of subjective well-being have been studied by many scholars from various points of view: the eudemonistic approach to understanding happiness, advanced by Aristotle; ideas about happiness M. Argyle, I.A. Dzhidaryan; the concept of psychological well-being N. Bradburn; the model of subjective well-being of $E$. Diener; the six-component concept of psychological well-being K. Ryff; understanding of the structure of subjective well-being proposed by E.N. Panina, G.V. Puchkova, L.V. Kulikov; N.K. Bakhareva, A.O. Prokhorov; model of development of subjective well-being O.V. Lucova; theoretical model of personal wellbeing N.A. Baturin, S.A. Bashkatova and N.V. Gafarova; the concept of subjective well-being R.M. Shamionov. In our understanding, subjective well-being is the response of the subject to external and internal stimulus, is associated with mental processes and properties, has certain temporal boundaries and is characterized by integrity.
We decided to study the phenomenon of subjective well-being, based on the developed by V.A. Labunskaya "multifactor socio-psychological model for studying attitudes toward appearance", based on integral cultural-psychological and sociopsychological factors. In this model, subjective well-being is one of the factors, since, on the one hand, it is a subject, and, on the other hand, its formation is due to the sociocultural conditions of human existence.

Based on this, the goal of our research is to identify the features of the subjective wellbeing of the individual and the relationship to their appearance of young men and women.

Research methods:

1) the scale of subjective well-being (the author of the Russian-language adaptation, V. M. Sokolov);

2) the method of "Estimated and informative interpretation of its external appearance and its compliance with gender-age constructs", developed by V.A. Labunskaya.

The empirical object of the research was 72 people, of whom 35 were girls and 37 boys between the ages of 18 and 20 .

In order to identify the features of the subjective well-being of the individual and attitudes towards their appearance in boys and girls, we used the method of ManWhitney. The results of the analysis are presented in table.
Based on the statistics of the $U$ MannWhitney statistics, the appearance and the masculinity / femininity of the appearance are significantly different in the group of (2) young men. There is also a tendency towards a difference in assessments of the significance of the social environment, satisfaction with daily activities, an integral assessment of the appearance, an assessment of the attractiveness of one's appearance and an assessment of satisfaction with one's appearance in the same group. They have significantly higher concerns about their appearance, but at the same time there is a tendency for them to have higher satisfaction with their appearance; much higher is the assessment of femininity / masculinity of appearance, there is a tendency to a higher appreciation of the significance of the socia environment, satisfaction with daily activities an integral assessment of the appearance, and an assessment of the attractiveness of one's appearance.
In our opinion, this suggests that young men as a whole assess their appearance somewhat higher than girls. They find their appearance attractive enough for the emergence of possible romantic relationships, they do not believe that their appearance lacks femininity or masculinity. Also for young men, the environment in general is somewhat more important than for girls, they are more satisfied with their daily activities. At the same time, the young men show great concern for their appearance in comparison with girls, who have a tendency to less high indices of self-appearance

Thus, we identified features of the subjective well-being of the individual and attitudes towards their appearance in boys and girls we found significant differences and tendencies towards them in assessing the level of subjective well-being and assessing the appearance of boys and girls. 